\title{
دراسة مدى تطبيق مفاهيم إدارة الجودة الشاملة فى المنظمات الصناعية بمدينة جدة - دراسة ميدانية
}

* د. نلفى عبد الفتاح شلبى

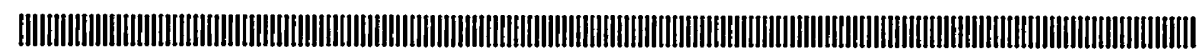

أرلا: مقلمة:

إن مسئولبة الادارة فى تحقيق أهداف المنظمة هي مسنولية تمثل تحديا كبيرا نظراً للعوامل

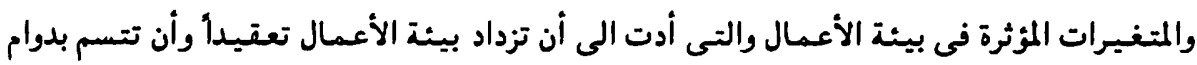

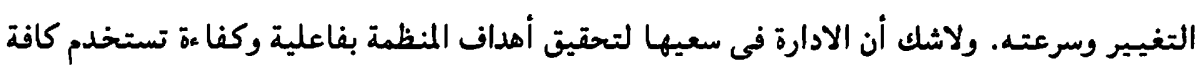
الأساليب المديثة التى يككن الاستفادة منها فى تحقيق تلك الاهداف.

ومن بين الاسـاليب المديثـة التى بدأت فى اليـابان والولايات المتـحسدة الامريكيـة وانتشـــ استخدامها عالمبا الاساليب الخاصة بالتحسين المستمر للجودة ، وقد تطورت هذه الاساليب بشكل كبير الى ان وصلت الى مرحلة أدارة الجودة الشاملة (TQM) .

"وإدارة الجودة الشاملة ( الكلية) (1) كما عرفها جوزيف جابلونسكى هى "شكل تعاونى لاداء الاعمال يعتمد على القدرات المشتركة لكل من الادارة والعاملين بهدف تحسين وزيادة الانتاجية بصفة مستـمرة من خلال فرت العمل" ، كما بعرفها مكتب الحسابات الفيدرالى فى واشنطن بالولايات

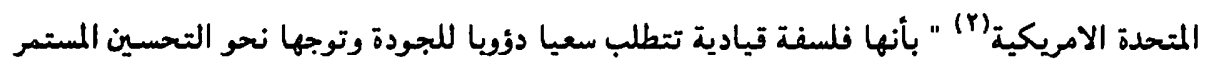
فى كافة جوانب العملية الادارية من إنتاج وخدمات وإجراءات واتصالات ، وأهم عناصر ادارة الجودة هى "القيادة والتركيز على العمبل والتحسين المستمر وتمكين العاملين والادارة وفق الحقائق".

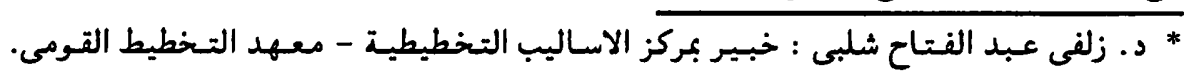
110 
إن إدارة الجودة الكلية (الشاملة) تمثل منهجا ووسيلة من أجل تحديد وتقليص الفاقد من وقت

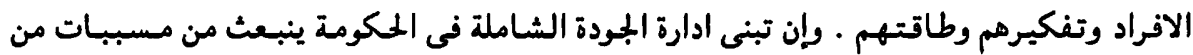

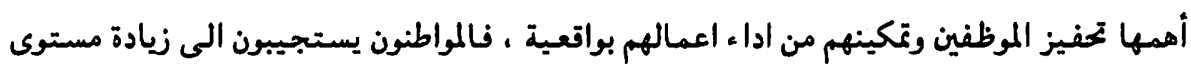

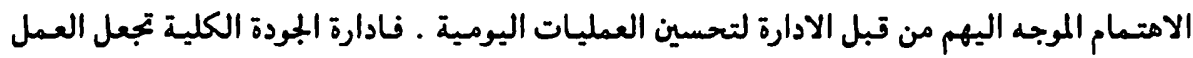

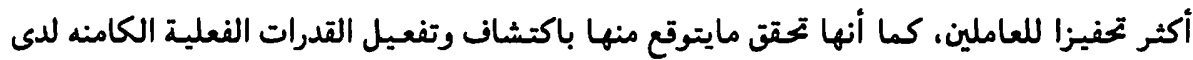
العاملين .

إن ادارة الجودة الشاملة هى اسلوب يحقق مزايا مزدوجة إذ يحقق مزايا للمستهللك أو العميل

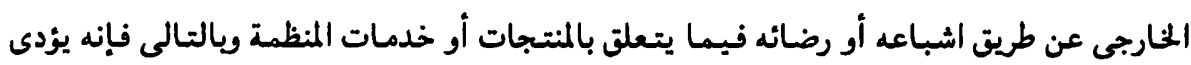
أيضا الى تحقيق مزايا ومكاسب للمنظمة ما ينعكس على ريحيتها لـ ـ وتصبح نتائج تطبيق مفهوم الجودة الشاملة مايلى: - الجى

تخفيض تكاليف التشغبل ، المرونه فى الوفاء بمتطلبات العملاء المتغيرة والمتجددة ، وتحويل

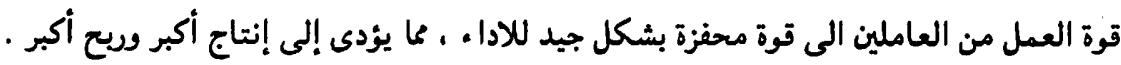
إن تطبيق الجهردة الشاملة يحقق للمنظمة مزايا عديدة شريطة أن يتم بعناية مع مراعاة كافة الشروط الواجب الالتزام بها فى عملية التطبيق.

\section{ثانيا: مشكلة الدراسة}

نظرا لأن بعض المنظمـات فى المملكة العريــة السعسودية مـازالت لاتهتم بالانظمـة والمفـاهيم الادارية المتعلقة بالجودة وتستخدم الاساليب التقليدية فى التخطيط والانتاج والعناية بجودة الانتاج

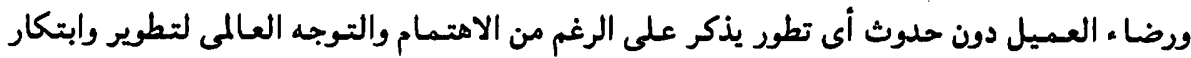

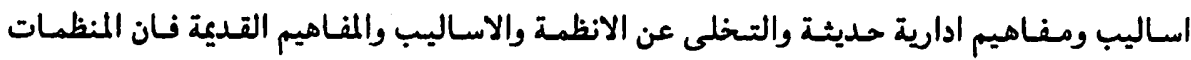

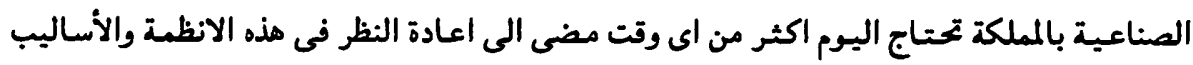

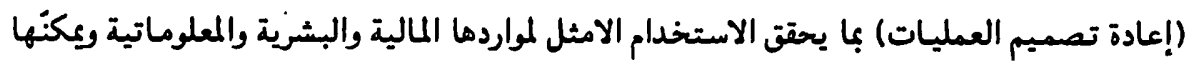

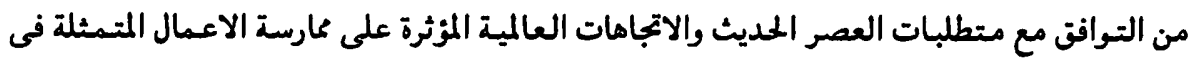
الآتى:

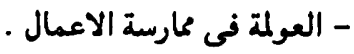




\section{- اتباع نظام حرية التجارة وإلغاء العديد من نظم الحماية الجمركية. \\ - تشجيع انشاء الشركات العالمية والصناعية والحدمية فى المنظمة . - ظهور التكتلات السياسبة العالمة.}

- ظهور اسواق جديدة لم تكن موجودة من قبل مع احتمال ظهور كيانات تنافسية فى المنظمة تحت مسمى السوق الشرق أوسطية.

وإجماع على ماسبق فلإن المنظمات الصناعية بالمملكة العربية السعودية سوف تعيش مأزتا حرجا وستواجه مناخا تنافسيا حادا إذا لم تواكب الاتجاهات العالمية الحديثة فى الادارة وتتخلى عن العني الانظمة والاساليب والمفاهيم القديمة.

ثالها : أهمية الدراسة

1 - يتعلق هذا البحث بالقطاع الصناعى وهو بلا شك قطاع حيوى وهام للاقتصاد الوطنى ولا

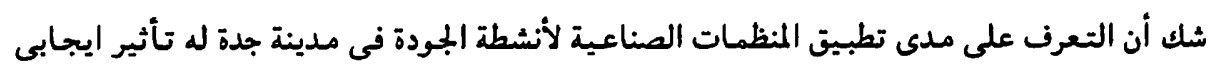
على الرفع من شأن القطاع الصناعى.

r- يهتم البحث بالاستفادة من أحد الاسالبب المديثة التى اتسع نطاق استخدامها فى الدول

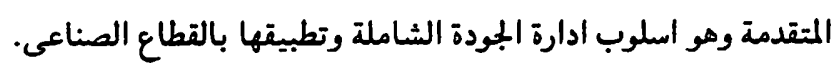
ب- يككن الاســــــادة مما يتـوصل اليه البحث من نتـائج فى مناطق اخـرى بالمملكة العربيـة السعودية والبلاد العربية.

\section{رابعا : أهداف الدراسة}

1- ابراز الخصانص والمزايا المتعلقة بموضوع جديد هو ادارة الجبودة الشاملة للاستفادة به فى تحسين جودة المنتجات السعودية والعربية .

ب- دراسة الوضع الراهن لمفهوم ادارة الجودة الشاملة فى المنظمـات الصناعبـة ومعرفـة مدى الاهتمام بأنشطة الجودة بشكل عام الوفع الراهن لمهرم

r- تقديم المقترحات بناء على نتائج الدراسة، وجود اتفاقيات دولية تعقد حاليا فى اجزاء IIV 
مختلفة فى العالم مثل اتفاقيات الجات.

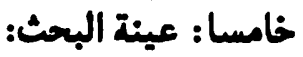

تم اختيار عينة لغرض هذه الدراسة شملت به مصنعا (لتسع صناعات مختلفة) والتى تتوقع

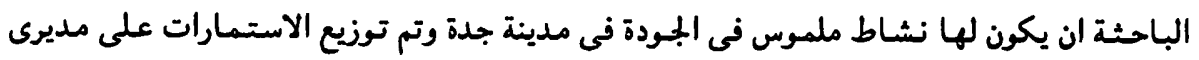

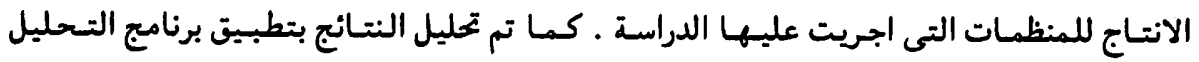
الاحصائى SPSS VER7.5 للوصول الى النتائج التى على ضوئها صيغت مجموعة من التوصيات. مادسا : التطود التاريخى لادارة الجودة الشاملة: مرت ادارة الجمودة الشاملة بثلاث مراحل حتى أصبحت فى شكلها الحالى وفيسـا يلى شرحا

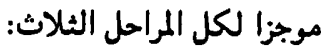

\section{المرحلة الاولى • 190}

في بداية الخمسينات ابرز المفكر الامريكى فيجى، بام A.V.Feigenbaum مفهوم الرقابة

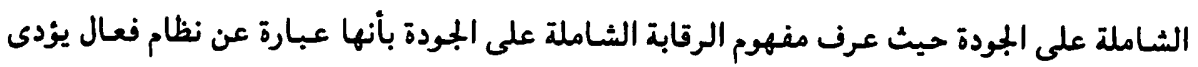

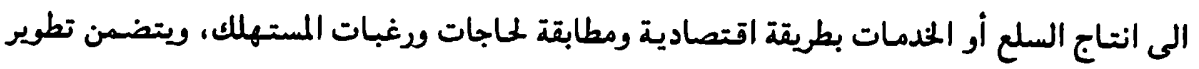

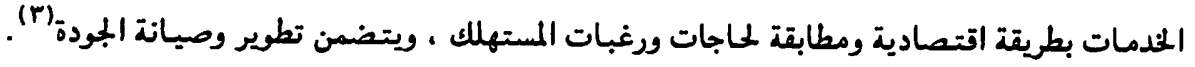

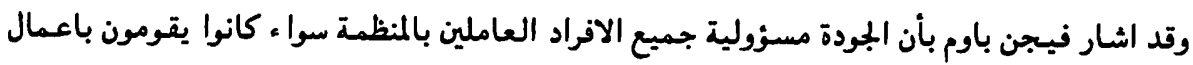

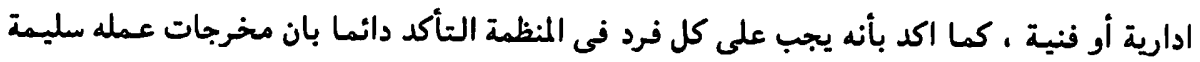

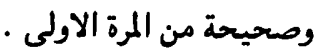

$$
\text { 1914. - 194. المرحلة الثانية }
$$

فى بداية الستينات ظهرت فلسفات جديدة للجودة وادارتها ، كان ابرزها فلسفة الرواد الاوائل للجودة وهم ادوارد دينج (Edward Deming) الذى وضع اربعة عشر مبدأ يكن للادارة فى المنظمات

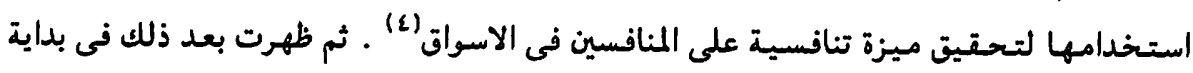

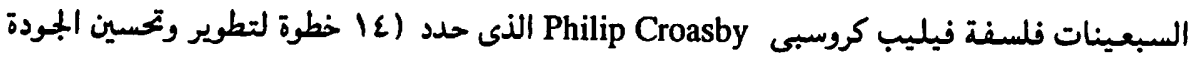
وادارتها) (o) . وأخيرا ظهرت فلسفة جوراندuran والذى اوضح ثلاثيات عمليات الجودة وهى تخطيط 


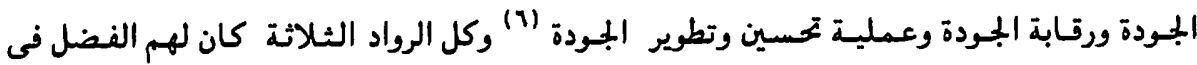
تحسين وتطوير الجودة وهم امريكيون وفلسفاتهم جميعا كانت تهدف الى تحقيق هدف واحد وهو العمل المستمر نحو تحسين الجودة.

المرحلة الثالثة والاخيرة .191 - 1990

حدثت فى آخر الثمانينات وبداية التسعينات تطورات كبيرة فى مفهوم الجودة وادارتها منها على سبيل المثال : نظام حلقات الجودة، وفريق الجودة، كما برز مفهوم الجودة كوظيفة اساسية للادارة وبرزت أهمية تطبيقه فى مجالات عديدة مثل الخدمات الصحية والرقابة البيئية وتوليد الطاقة النووية

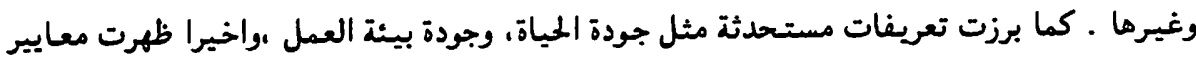

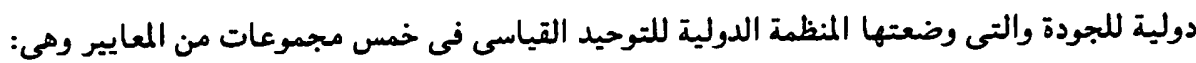
.ISO 9000- 9004

كل هذه المفاهيم بالاضافة الى نظريات الرواد الثلاثة للجودة كانت الاساس لها يعرف فى كل العالم اليوم بمفهوم ادارة الجودة الشاملة.

\section{سابعا: أهمية ادارة الجمودة الشاملة}

أصبحت الجودة فى هذا العصر هى الاساس للاتصالات التجارية بين الدول وهى التى تقرر نجاح

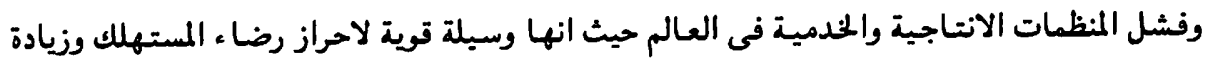

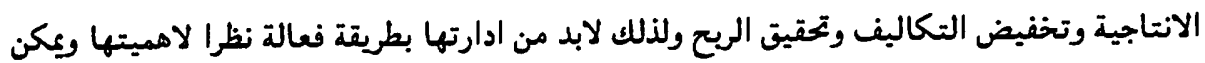
اجمال اهمية ادارة الجودة الشاملة فى النقاط التالية: 1- ان نظام الجودة الشاملة يؤدى الى تخفيض التكلفة وزيادة الريحية .

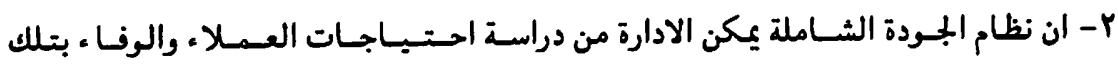
الاحتياجات. r- فـ ظل الظروف التنافسية التى تعيشها مؤسسات الاعــال يساهم مدخل ادارة الجودة الشاملة فى تحقيق ميزة تنافسية فى السوق. ع- ان تطبيق مدخل ادارة الجودة الشاملة اصبح امرا ضروريا للحصول على بعض الشهادات

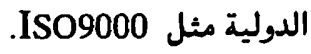


0- المساهمة فى اتخاذ القرارات وحل المشكلات بسهولة ويسر.

1- تدعيم الترابط والتنسيق بين ادارات المنشأة ككل .

V - التغلب على العقبات التى تعوق اداء الموظف من تقديم منتج ذى جودة عالية.

1- تنـــــة الافراد والشعـور بوحـدة المجــوعة وعـمل الفريق والاعـمال المتبـادلة بين الافراد

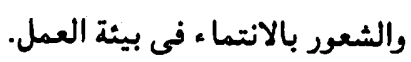

9- توفير مزيد من الوضوح للعاملين وكذلك توفير المعلومات المرتدة لهم وبناء الثقة بين أفراد

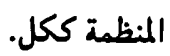

.

11 - احراز معـدلات اعلى من التـفوق والكفاءة عن طريق زيادة الوعى بالجمودة فى جــيع

ادارات المنظمة.

r ا - تحسين سمعة المؤسسة فى نظر العملاء والعاملين.

\section{(v) ثامنا : عناصر ادارة المجودة الثاملة}

هناك خلاق بين الكتاب والباحثين على عدد عناصر ادارة الجودة الشاملة. فبعض الكتاب يؤكد

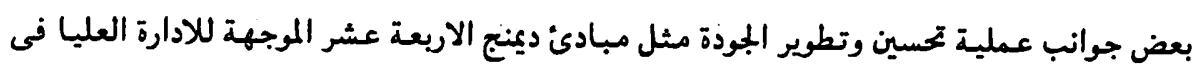

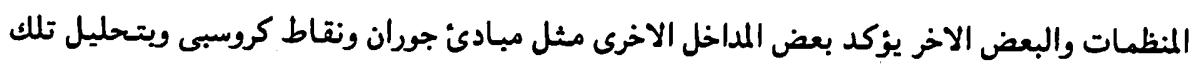

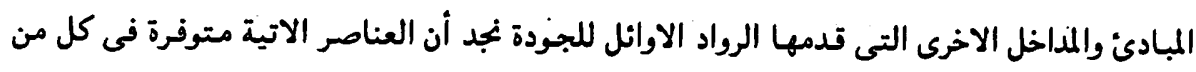
المبادئ والمداخل الاخرى لعملية تحسين وتطوير الجودة والعملِيات الانتاجية:

سياسة الجمودة - مراجعة العقود - دليل الجودة - المعايير - نظام الجودة - تحليل تكاليف الجودة - ضبط العمليات - الفحص والاختبار - التدريب - مراجعة الجودة - سجلات الجودة.

تاسعا: الوضع الرامن لتطبيق مفهوم ادارة الجمودة الثاملة فى المنظمات الصناعبة بدينة جدة قامت الباحثة بدراسة ميدانية استهدفت معرفة واقع حال مفهوم ادارة الجودة الشاملة فى 
المنظمات الصناعبة بدينة جدة ـ وتم توزيع استمارة الاستبيان على مديرى الانتاج لعدد له مصنعا (لتسع صناعـات مـختلفة ) وباستطلاع ارائهم حول مـدى تطبـيق مفهـوم ادارة الجمودة الشـاملة فى المنظمات الصناعية كانت الاجابات كالتالى:

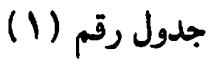

مدى تطبيق ادارة الجودة الشاملة فى المنظمات

\begin{tabular}{|c|c|c|}
\hline النسبة المثوية & عدد المنظمات & البيان \\
\hline $\begin{array}{l}\% q \varepsilon, 1 \\
\% 0, v \\
\% r, r\end{array}$ & $\begin{array}{l}\varepsilon q \\
r \\
17\end{array}$ & يطابق المفهوم \\
\hline
\end{tabular}

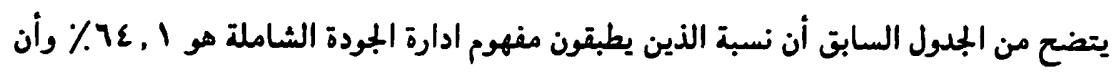

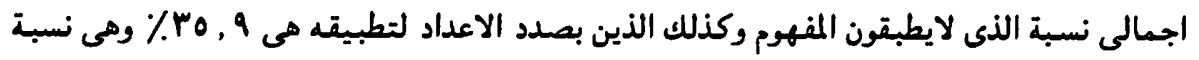

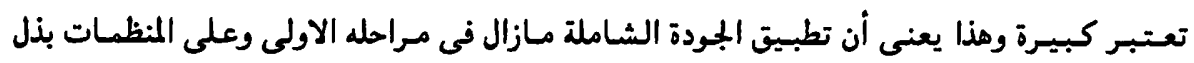
مجهود كبير من اجل تبنى برنامج ادارة الجودة الشاملة. وعند سؤال المبحوثين عن سبب عدم تصميم نظام ادارة الجودة الشـاملة فى منظماتهم كانت

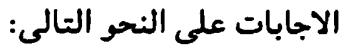

جدول رقم (Y) (r)

اسباب عدم تطبيق مفهوم ادارة الجودة الشاملة

\begin{tabular}{|c|c|}
\hline عدد المنظمات & اسباب عدم تطبيق المفهوم \\
\hline 9 & 1- ارتفاع التكلفة \\
\hline $1 \varepsilon$ & ץ- عدم توافر المتخصصين فى هذا المجال \\
\hline$\checkmark$ & r- النقص فى المهارات لدى العاملين \\
\hline$y$ & ع- مفهوم ادارة الجودة الكلية غير واضح \\
\hline 0 & 0- عدم اقتناع الادارة بجدوى التطبيق \\
\hline
\end{tabular}


ويظهر من الجمدل السابق بأن اسباب عـدم تطبيق نظام ادارة الجمودة الشـاملة فى المنظمات

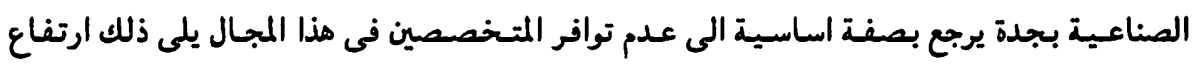
التكلفة لتطبيق هذا النظام وكذلك النقص فى المهارات لدى العاملين وان مفهوم الجودة غير واضح وقد ئد

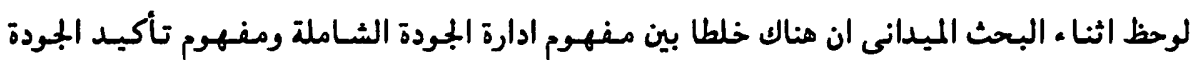

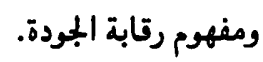

مما سبق يتضح الوضع السيى لانشطة الجودة فى المنظمات الصناعية بدينة جدة. ويسزال مديرى الانتاج هل المصنع لديه علامة جودة أو شهادة مطابقة والتى تمنح من قبل الهيئة العربية السعودية للمواصفات والمقاييس كانت الاجابة كالتالى: جدول رقم (r)

مدى حصول المصنع على علامة الجودة او شهادة المطابقة

\begin{tabular}{|c|c|c|}
\hline النسبة المثوية & عدد المنظمات & البيان \\
\hline$\% 0.9$ & rY & نعم المصنع حاصل على علامة الجودة \\
\hline$\% 29,1$ & ry & لا المصنع غير حاصل على علامة الجودة \\
\hline
\end{tabular}

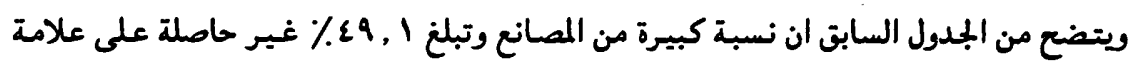

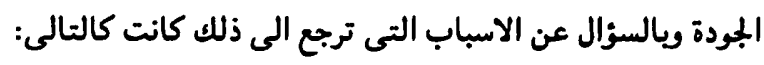

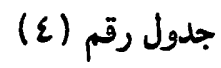

اسباب عدم حصول المصنع على علامة الجودة (عدة

\begin{tabular}{|c|c|c|}
\hline النسبة المثوية & عدد المنظمات & الاسباب \\
\hline$\%$ Ir, r & v & ارتفاع المواصفات التى تضعها الهيئة \\
\hline$\%$ Ir, r & $v$ & عدم امكانية الالتزام بمواصفات الهيئة \\
\hline$\% Y r, 7$ & rq & عدم الحاجة اليها \\
\hline
\end{tabular}


يتضح من الجدول السابق أن الاسباب التى ترجع الى عدم حصول المنظمة على علامة الجودة هى

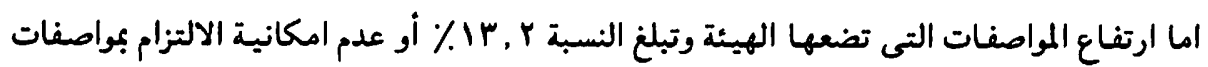

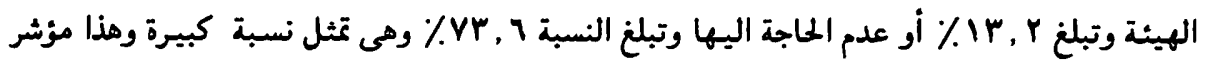
على عدم اهتمام عدد كبير من المنظمات بتطبيق مفاهيم ادارة الجودة الشاملة بادارتها. (1) سياسة الجودة يجب على الادارة العليا بالمصنع أو الشركة أن تحدد سياستها وأهدافها بالنسبة للجودة فى شكل مكتوب ورسمى على أن تكون هذه السياسة منشورة ومفهومه ومعلنه لجميع العاملين بالمنظمة بدءا من المدير التنفيذى وحتى اصغر موظف والهدف الرئيسى من وجود سياسة للجودة فى المنظمة هو التأكد من أن الجودة أصبحت محل اهتمام كل فرد وكل قسم داخل المنظمة. وبتحليل نتائج الاستبيان لمعرفة مدى توفر سياسة الجودة فى المنظمة الصناعية بجدة كانت النتبجة كالتالى: - n

$$
\text { جدول رقم (0) }
$$

مدى توفر سياسة الجودة فى المنظمات الصناعية

\begin{tabular}{|c|c|c|}
\hline النسبة المثوية & عدد المنظمات & السياسة \\
\hline$\% \wedge \Lambda, \vee$ & $\varepsilon V$ & توجد سياسة للجودة \\
\hline$\% 11, r$ & 7 & لا توجد سياسة للجودة \\
\hline
\end{tabular}

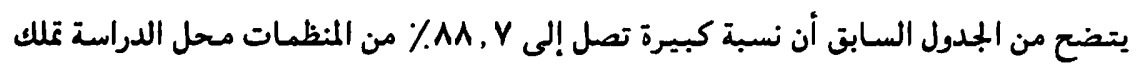

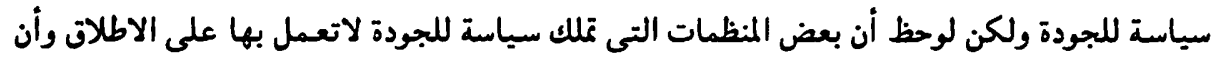
تلك السياسات موضوعة فى ادراج المكاتب لايعرف عنها العاملون شيئا.

\section{مراجعة العقد}

إن مراجعة العقد قبل العمل والتنفيذ لضمان تأكبد الججودة يعتبر جزءا هامـا فى نظام الجمودة وعنصرا أساسيا من عناصر ادارة الجودة الشاملة حيث يحقق الفوائد التالية: 
- المساهة فى تنفيذ العقد - إشراك كل المهتمين بمراجعة العقد - - | - تسهيل عملية مراجعة الجودة مع العميل اما النواحى التى يجب أن تؤخذ فى الاعتبار فى حالة مراجعه العقد فهى عديدة وأهمها: - التأكد من أن المتطلبات حددت تحديدا واضحا وتم توقيعها. - الاجراءات التعاقدية فيما يتعلق بجودة المنتج - التأكد من أن المنظمة لديها الامكانيات المختلفة للوفاء بتطلبات العقد. ويتحليل نتائج الاستبيان كانت نتائج الدراسة كالتالى:

جدول رقم (7)

مدى توفر اجراءات المراجعة للعقود قبل تنفيذها

\begin{tabular}{|c|c|c|}
\hline النسبة المثوية & عدد المنظمات & البيان \\
\hline$\% \wedge \Lambda, \wedge$ & $\varepsilon V$ & توجد اجرا ءات لمراجعة العقد \\
\hline$\% 11, r$ & 4 & لاتوجد اجرا ءات لمراجعة العقد \\
\hline
\end{tabular}

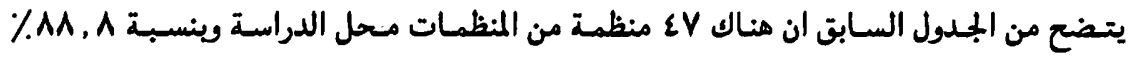

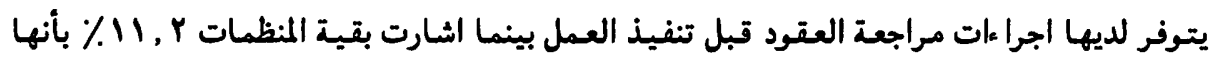
لاتملك اجراءات لمراجعة العقد قبل تنفيذه .

\section{دليل المجودة}

يعتبر دليل الجودة من أهم متطلبات ادارة الجودة الشاملة لذلك فوجوده فى إلمنمات الصناعبة

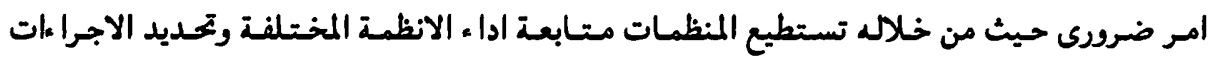

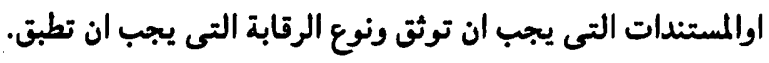
وقد أشار كثير من الكتاب والباحثين الى الفوائد والمزايا العديدة التى تحصل عليها المنظمات 
فى حالة امتلاكها لدليل الجودة ( ـ1") ومن اهم تلك الفوائد: ا - تعريف العاملين والمتعاملين بنظام الجودة والفوائد التى يمكن تحقيقها من النظام. r- بهولة التنسيق بين الادارات فى المستويات الادارية المختلفة . r- الزام الموردين بالجودة المناسبة فى توريداتهم. ع- المساهمة فى تكوين انطباع جيد وسمعة طيبة للمنظمة المردية بالنسبة لتوفر دليل الجودة فى المنظمات الصناعية بدينة جدة كانت النتانج كالتالى: جدول رقم (V)

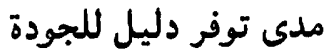

\begin{tabular}{|c|c|c|}
\hline النسبة المثوية & عدد المنظمات & البيان \\
\hline$\% 49,1$ & rV & يوجد دليل للجودة بالمنظمة \\
\hline$\%$ Ir, r & $v$ & لايوجد حتى الان دليل للجودة \\
\hline$\%$ IV & 9 & نحن فى طور الاعداد للدليل \\
\hline
\end{tabular}

ويتضح من النتائج السابقة ان نسبة المنظمات التى لديها دليل للجودة هى ^ ـ \9٪ ونسبة

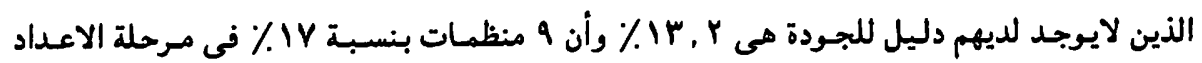
للدلبل.

وقد برر مديرو الانتاج فى المنظمات التى لاتللك دليلا للجودة بأن عدم توفر دليل للجهودة فى

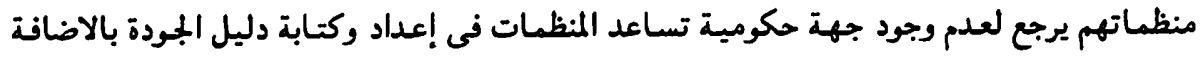
الى عدم قدرة الكوادر الفنية للمنظمة للقيام بإعداد الدليل.

(iI) نظام الجودة

ويصدد هذا النظام تقوم ادارة المنظمة باعـداد كتـيب للجبودة والذى يجب أن يكون مناسبـا لمستوى نظام الجودة وغالبا مايحقق كتيب نظام الجودة مايلى:

- تعريف العاملين والمتعاملين بنظام الجودة والفوائد التى يمكن أن يحققها لهم والمنظمة ككل. 
- سهولة التنسيق بين الادارة العليا والوسطى والدنيا بالمنظمة . - إلزام الموردين بالجودة بخصوص توريداتهم. - المساهمة فى تكوين انطباع جيد عن المنظمة وبغض النظر عن ذلك يجب أن يوفر الكتيب احتـيـاجات نظام الجودة والمعتــد على نظام ISO كما يجب على الادارة اتخـاذ الخطوات اللازمة لتطبيقه بفاعلية.

ولمعرفة مـدى توفر نظام الجمودة فى المنظمات الصناعيـة بمدينة جدة من عدمه تم استقصـاء.

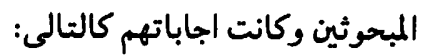

$$
\text { جدول رقم (1) - (1) - (1) }
$$

مدى توفر نظام الجودة مدم

\begin{tabular}{|c|c|c|}
\hline النسبة المئوية & عدد المنظمات & البيان \\
\hline$\%$ Yr, 1 & rq & يوجد نظام للجودة \\
\hline$\% 0,7$ & $r$ & لايوجد نظام للجودة \\
\hline$\% 1 \wedge, 9$ & 1. & نظام الجودة فى طور الانشاء \\
\hline$\% 1,9$ & 1 & لاتوجد نية لدى المنظمة لانشائه \\
\hline
\end{tabular}

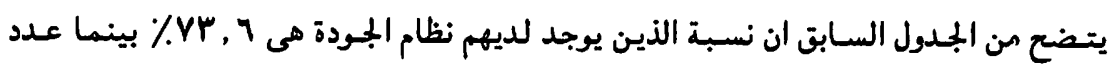

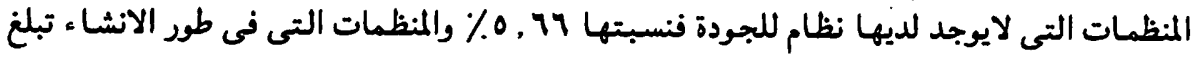
. $11 \wedge, 9$

(Ir) مراقبة العمليات تطبيق ادارة الجودة الشاملة فى اي منظمة من المنظمات يتطلب توفر نظام فعال للجودة يتم من

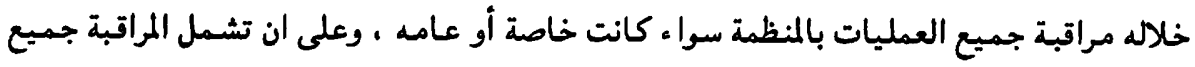

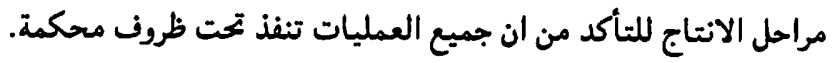
ولمعرفة مدى توفر اجراءات المراقبة على العمليات تم استقصا ء المبحوثين وكانت اجاباتهم على

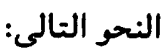




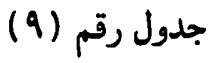

مدى توفر اجراءات لمراقبة العمليات

\begin{tabular}{|c|c|c|}
\hline النسبة المثوية & عدد المنظمات & البيان \\
\hline$\% 94, r$ & 01 & توجد اجراءات لمراقبة العمليات \\
\hline$\%, \wedge$ & r & لاتوجد اجراءات لمراقبة العمليات \\
\hline
\end{tabular}

يتضح من الجدول السابق ان Y ، 94\% تقريبا من المنظمات التى اجابت على الاستبيان اشارت

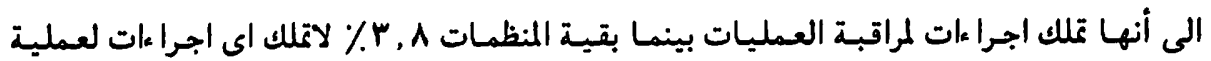

الفحص والاختبار: (ir)

للوصول الى نظام جودة فـعال يتطلب الامر القيام بعملية الفحص والاختبـار وتتضمن هذه

- تحديد المستندات المستخدمة فى الفحص .

- فحص واختبار المنتجات المشتراه من المورد. - فحص واختبار المواد اثناء التشغيل.

- التأكد من أن المنتجات النهائية تتطابق مع المواصفات المحددة من قبل المناد المبأة والعميل - المعلومات التى يجب تسجيلها نتيجة لعملية الفحص. ويالنسبة لعملية الفحص والاختبار فى المنظمات الصنتاعبة بمدينة جدة وجد أنها تحظى باهتمام كبير حيث كانت نتيجة الدراسة كالتالى:

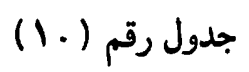

مدى توفر اجراءات الفحص واختبار المنتج

\begin{tabular}{|c|c|c|}
\hline النسبة المثرية & عدد المنظمات & البيان \\
\hline $\begin{array}{l}\% \wedge \Lambda, \vee \\
\% 11, r\end{array}$ & $\begin{array}{l}\varepsilon V \\
y\end{array}$ & توجد اجراءات للفحص واختبار المنتج \\
\hline
\end{tabular}




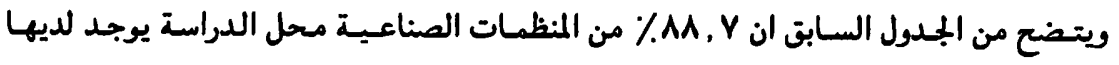
اجراءات للفحص واختبار المنتج وهى تعنى ان هناك نسبة كبيرة تحظى باهتمام كبير لهذا الجانب. التبريب

من المعروف أنه يجب تحديد الاحتياجات التدريبية بالنسبة للافراد المشاركين فى تطوير وتحسين

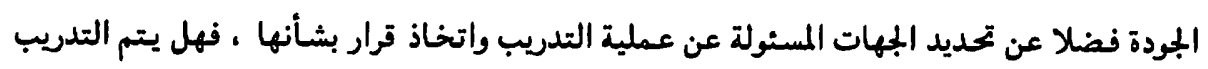
داخليا ام خارجيا ؟ أبرده

وماهى المواصفات التى يجب توافرها فى القائمين بعملية التدريب؟ وماهى خبراتهم العملية

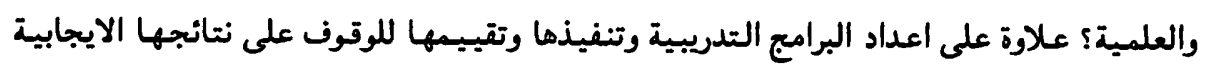
والسلبية ومن ثم التمكن من التخطيط العلمى المستقبلى لانشطة التدريب على الجودة. ولمعرفة مدى توفر نظام للتدريب على الجودة فى المنظمات الصناعية من عدمه كانت اجابات

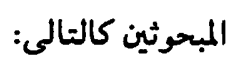

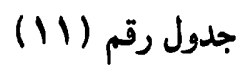
مدى توفر نظام للتدريب

\begin{tabular}{|c|c|c|}
\hline النسبة المثرية & عدد المنظمات & البيان \\
\hline $\begin{array}{l}\% \wedge \Lambda, \vee \\
\% 11, r\end{array}$ & & تلا توجد برامج تدريبية بالمنظمة \\
\hline
\end{tabular}

ويتضح ما سبق ان هناك نسبة كبيرة من المنظمات لديها برامج تدريبية للجودة تصل إلى VA V Y

النتائج :

من التحليل السابق توصلنا الى النتائج الاتية:

ا - اظهرت الدراسة ان تطبيق مفهوم ادارة الجودة الشاملة لايزال فى مراحله الاولى حيث وجد ان

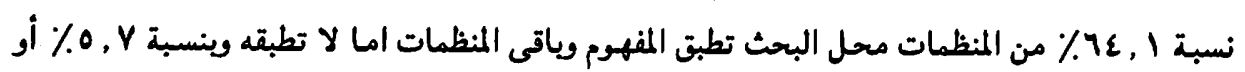




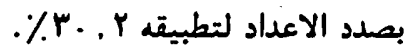

r- اوضحت الدراسة ان اسباب عدم تطبيق نظام ادارة الجودة الشاملة فى المنظمات الصناعية

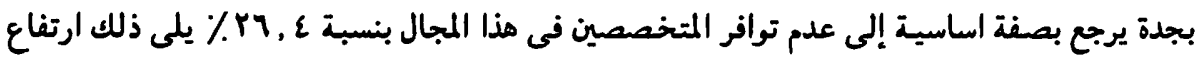
التكلفة لتطبيق هذا النظام وكذلك نقص المهارات لدى العاملين وان مفهوم ادارة الجودة الشاملة غير

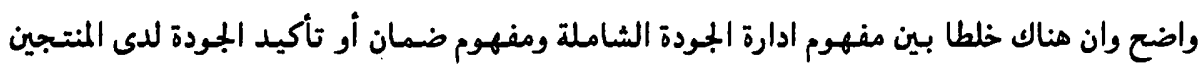
والعاملين.

r- اوضحت الدراسة ان هناك نسبة من المصانع محل الدراسة وتبلغ ا , 9£٪ غير حاصلة على

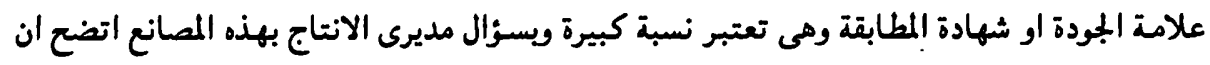

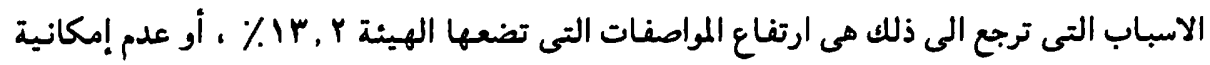

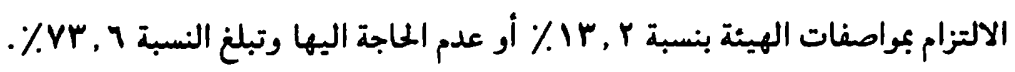
ع - اظهرت النتائج ان نسبة المنظمات محل الدراسة التى لديها سياسة واضحة للجودة تبلغ

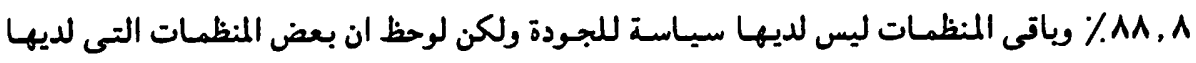

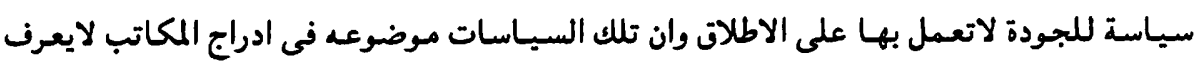
عنها العاملون شيئا.

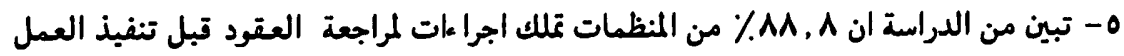

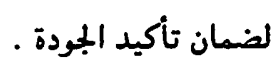

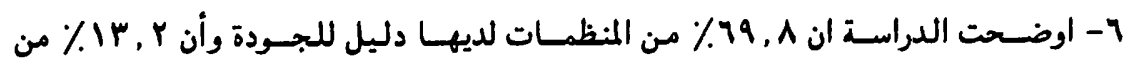

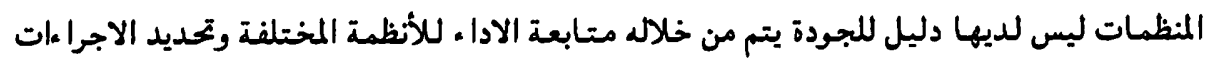

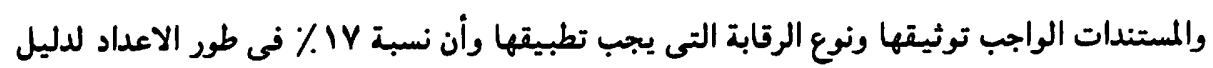
الجودة.

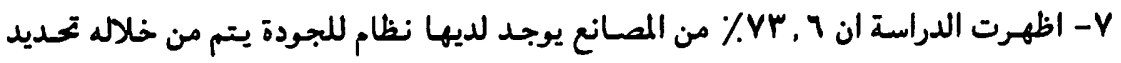

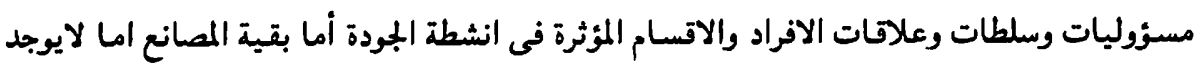

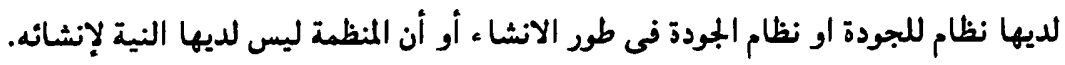
A- اظهرت النتائج أن r , 9 ٪ من المنظمات يتـوفر لديها نظام لمراقبة العمليات الانتاجية 


\section{ومعدات قياسية بالاضافة الى الرقابة البشرية.}

9- تبين من الدراسة ان عملية الفحص والاختبار للمواد المثتراه أو المنتجة داخل المنظمة تحظى

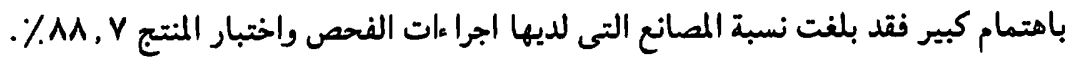
• 1- أوضحت الدراسة أن نسبة المنظمات التى لديها برامج تدريبية تساهم فى تحسين وتطوير

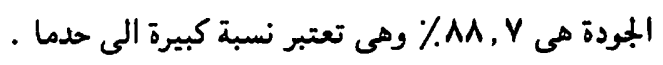

التوصيات : (n)

ا- يجب تنمية الوعى نحو الجودة لدى كافة مديرى الادارات ورؤساء الأقسام والعاملين .

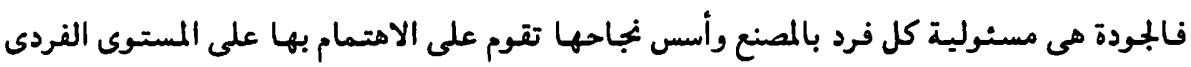

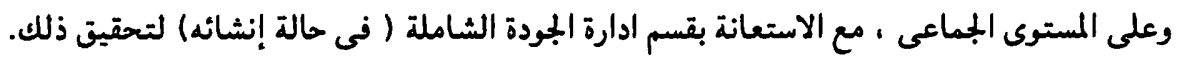

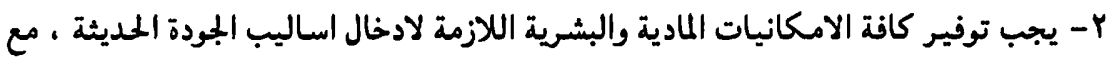

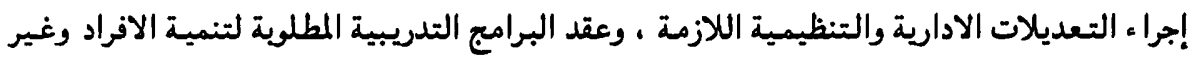
ذلك من متطلبات لاتمام جهود تطبيق اسالبب الجودة الشاملة. r- على المنظمات الصناعية التى ليس لديها دليل للجودة اعداد دليل للجودة وعلى تحديد

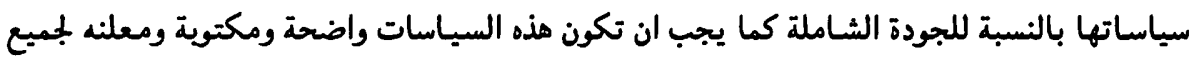
العاملين بالمنظمة.

ع- الاهتـــام بانشـاء وتطبـيق أنظمـة الجـودة فى كل المنظمات والتى من خلالها يتم تحـديد

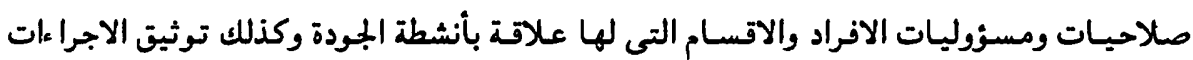
المتعلقة بالفحص والاختبار والمعايير والضبط لجميع إلنشطة المؤثرة فى الجودة. ه- تحديد جائزة سنوية للجودة تعطى من قبل الحكومة للمنظمة التى حققت مستوى عاليا من

الجودة لمنتجاتها.

1- اخيرا يجب أن لاتكون الجودة على المنتجات الصناعية فقط ولكن يجب ان تصبح الجودة

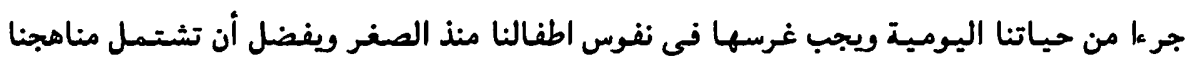

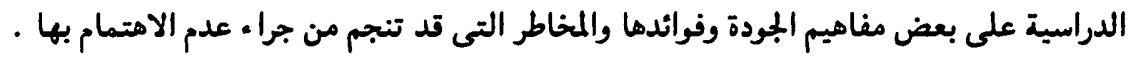




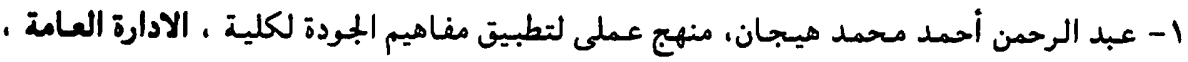

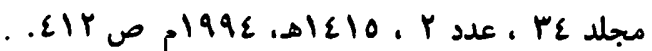

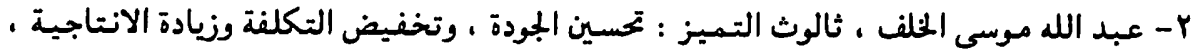

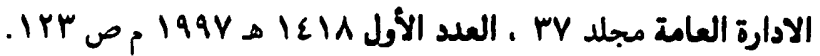
3-Feigenbaum, Armand V. (1986) Total Quality Control McGraw-Hill, NewYork. P1115.

4-Deming, W.Edwards (1982) Improvement of Quality and Productivity through Action by Management. National Productivity Review winter (1982) p.159.

5- Milahovech, Michael E. (1991) Total Quality Management in the Public Sector , National Productivity Review Spring (1990)P. 159

6- Juran, J,M. and Gryna F.Quality planning and analysis. Second Edition (New Delhi, 1983) P. 116 .

V- أحمد محمد الشامى • إدارة الجودة الشاملة : المفهوم والتطبيق فى الجمهورية اليمنية - الادارى العدد Vو مارس 1999.

^- توفيق محمد عبد المحسن · إدارة الجيودة الشاملة كمدخل لتحسين الادا ـ ، دار النهضة العربية

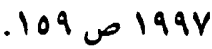

9- توفيق محمد عبد المحسن . تخطيط ومراقبة جودة المنتجات كمدخل لتحسين الادا ـ ، دار النهضة

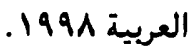
ـ ا ادريجى باريو . الدليل الصناعى الى ايزو . . .9. دار الفجر اللنشر والتوزيع 1990.

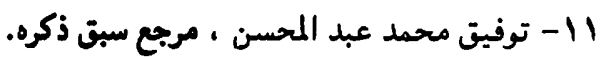

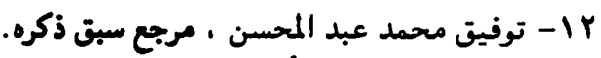

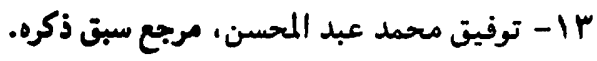
ع ا - توفيق محمد عبد المحسن، مرجع سبق ذكره. 
- فوزى شعبان مدكور ـ ادارة جودة الانتاج ـ مركز جامعة القاهرة للتعليم المفتوح 1990.

- Ajit Singh . TQM productivity. vol. 23 No. 3 Dec.1989

- Cullen, J.H. Implementing Total Quality. IFS publications Ltd., London 1987.

- Deming, W.E.Quality . Productivity, and Competitive position, MIT Center for Advanced Engineering Study, Cambridge Mass. 1982.

- Feigenboum, A.V.Total Quality Control. 3rd ed. New York Mcgraw Hill Book Company 1983.

- Pulat, B.M. Total Quality Management: A Framework for Application in Manufacturing. The TQM Magazine, vol 6, No.1 , 1994.

- Scbotes, P.R. "Total Quality or performonce Appraisal . Choose one," National Productivity Review, Summer 1993..

- Walker, J.Brent's . Total Quality programme, The TQM Magazine vol. 6, No.4 1994. 